\title{
The Use of a PAE /Bentonite Binary System to Improve the Wet Strength of Paper
}

\author{
Shuai-Bo Liang, Xiao Ning, Qing-Jin Fu, Qian Liu, and Chun-Li Yao* \\ Bentonite and polyamidoamine epichlorohydrin (PAE) resin were added \\ sequentially as a binary system to improve the properties of the paper, \\ especially the wet strength. The results showed that the dry tensile index, \\ the wet tensile index, and the folding endurance of the paper could be \\ improved with only the use of polyamide polyamine epichlorohydrin resin. \\ However, a binary system of polyamide polyamine epichlorohydrin resin \\ and bentonite was more effective. When $0.8 \%$ polyamide polyamine \\ epichlorohydrin resin and $0.75 \%$ bentonite were added, the dry tensile \\ index, the wet tensile index, and the folding endurance of the paper \\ increased by $37.8 \%, 2780 \%$, and $281 \%$, respectively, when compared to \\ the control sample. The measurements of the water retention value and \\ the percent fines retention of the pulp showed higher values after being \\ treated with the binary system than being treated by polyamide polyamine \\ epichlorohydrin resin alone. Scanning electron microscopy analysis \\ indicated that a binary system of polyamide polyamine epichlorohydrin \\ resin and bentonite could increase the combination of fibers in paper.
}

Keywords: Binary system; Bentonite; Wet strength; Paper properties

Contact information: a: Beijing Key Laboratory of Lignocellulosic Chemistry, Beijing Forestry University, Beijing, 100083 China; *Corresponding author: chunliyao2006@163.com

\section{INTRODUCTION}

With the continued development of the economy and improvements in the standard of living, the quality of paper that individuals require continues to increase. Both the dry strength and the wet strength of paper are important attributes that affect the reliability of the paper (Hubbe et al. 2007; Hubbe 2014). The term "wet strength" refers to the strength of the finished paper or paperboard after it has been moistened with water. Wet strength is also expressed as a percentage of the post-wetting strength and the initial wet strength. Paper products placed in an aqueous medium that retain a substantial portion of their initial dry strength over time are considered to have good wet strength.

Wet strength is particularly important for many types of paper products, which are in frequent contact with water or used in a humid environment, such as packaging paper, carrier paperboard, liquid packaging base paper, tissues, and towels (Aracri et al. 2011). Numerous practices have shown that the most practical way to improve the wet strength of paper is via the use of a wet strength agent (Bai et al. 2017).

In recent years, many types of wet strength agents have been developed to meet production requirements, such as urea-formaldehyde resin (UF), melamine formaldehyde resin (MF), polyamide glycolaldehyde, polyamide glycolaldehyde (PEI), dialdehyde starch (DAS), polyamide polyamine epichlorohydrin resin (PAE resin), etc. (Gärdlund et al. 2003; Sun et al. 2010; Chen et al. 2013; Deutschle et al. 2014; Wu et al. 2018). Among these, PAE resin is one of the most commonly used wet strength agents. It is synthesized 
from polyamideamine chains reacting with epichlorohydrin. This results in the formation of a unique four-membered 3-hydroxy-azetidinium ring at approximately $80 \%$ of each amideamine repeating unit together with partial cross-linking between the polyamideamine chains via 2-hydroxypropane bridges originating from the attached epichlorohydrin (Obokata and Isogai 2005; Obokata and Isogai 2007). When compared with UF and MF, it has many superior properties, such as the lack of free formaldehyde, good retention on the surface of the fiber, a high level of paper softness without the addition of other additives, little effect on the whiteness of the paper, and suitability for a neutral to alkaline $\mathrm{pH}$ papermaking system.

Various mechanisms have been proposed to explain wet strength enhancement via PAE resin. On the one hand, it has been proposed that there is a reaction between the azetidinium groups and the anionic sites on the fibers and fines (primarily carboxyl groups), which results in the formation of covalent bonds that are non-water-soluble. Alternatively, it has been proposed that the PAE resin undergoes a self-crosslinking mechanism, which forms a water-insoluble PAE resin network (Obokata and Isogai 2007).

During production, many grades of paper require high dosage levels of PAE resin to achieve the required wet tensile specifications. However, the total amount of the PAE resin that can be adsorbed into the cellulose fibers is limited by the anionic charge density of the fibers (Hubbe et al. 2003). If not properly managed, the unretained wet strength resins will accumulate in the white water system, which leads to poor machine dewatering, wire and felt filling, sheet breaks and holes, and increased defoamer usage (Hubbe 2014). To overcome these unwanted effects, the system charge is often balanced by applying anionic chemicals such as carboxymethyl cellulose (CMC), sodium alginate (SA), microcrystalline cellulose (MCC), and nano-crystalline cellulose (NCC) (Aarne et al. 2012; Su et al. 2012; Siqueira et al. 2015; Sun et al. 2015; Bai et al. 2017; He et al. 2017; Ning et al. 2018).

Bentonite is a widely available and abundant natural mineral, usually used as a low cost adsorbent in water and wastewater treatment, due to its net negative surface charge (Anirudhan and Ramachandran 2015; Toor et al. 2015; Huang et al. 2017; Pandey 2017). However, the application of bentonite as a paper strength additive, previous to this study, was rarely examined. In theory, bentonite, with a net negative surface charge, coupled with PAE resin could further improve the mechanical strength of paper sheets compared to the addition of PAE resin alone.

In this study, bentonite was added sequentially with PAE resin as a binary system to enhance the mechanical properties of the cellulose fiber networks. The effect of the dosage of bentonite on the properties of the paper, the fines retention rate, and the water retention value (WRV) of the pulp were investigated. In addition, the enhancement mechanism of the binary system was researched.

\section{EXPERIMENTAL}

\section{Materials}

The aspen kraft pulp board used in this study was provided by the Hunan Yueyang Paper Group (Hunan, China). The pulping conditions were as follows: a sulfidity of $1.8 \%$, an active alkali of $15.2 \mathrm{~g} / \mathrm{L}$, a maximum temperature of $168{ }^{\circ} \mathrm{C}$, a total heating time of 1.8 $\mathrm{h}$ to $2 \mathrm{~h}$, a $45 \%$ yield, and a beating degree of $40^{\circ} \mathrm{SR}$. The cationic PAE resin used in this study was a commercial product from Xinquan Paper Additives Co. (Shandong, China) in 
the form of a $12.5 \%$ water solution. The solution was prepared via dilution with deionized water before each use to ensure its freshness. The bentonite was supplied by Hengxin Filter Factory Co. (Henan, China). All the chemicals used were of analytical or reagent grade and used without further purification.

\section{Methods}

Handsheet methodology

The pulp fibers were swelled, disintegrated, and beaten to the desired degrees. An aqueous pulp suspension (with a concentration of $16 \mathrm{~g} / \mathrm{L}$ ) was obtained with a pulp disintegrator. With a dry pulp mass of $2.512 \mathrm{~g}, 0.8 \%$ PAE resin was first added to the pulp slurry, stirred for 15 minutes and then the bentonite $(0.25 \%, 0.5 \%, 0.75 \%$, and $1.0 \mathrm{wt} \%$.) was added and stirred for 15 minutes. For each condition, at least five standard handsheets, with a target grammage of $80 \mathrm{~g} / \mathrm{m}^{2}$, were prepared via a round handsheet former with a diameter of $200 \mathrm{~mm}$ according to the ISO 5269-2 (2004). The control handsheets were made following the same methodology, but without the addition of any additives. Finally, the handsheets were conditioned at $23^{\circ} \mathrm{C}$ and $50 \%$ relative humidity, for at least $24 \mathrm{~h}$ before the physical testing was performed.

\section{Measurement and analysis of the handsheets}

The density, dry tensile index, wet tensile index, and folding endurance were measured using the relevant standard methods. Density was measured based on the ISO 534 (2011) standard. The tensile index is commonly applied to represent the tensile strength of the paper. The wet strength was defined as the ratio of the wet tensile strength of the treated handsheets to the dry tensile strength of the control sample. The dry and wet tensile indexes of the handsheet strength were tested according to TAPPI standard T220 sp-01 (2011). The folding endurance was measured according to TAPPI standard T511 om-08 (2008) method. Ten samples were measured for each handsheet condition to obtain an average result.

\section{Measurement of the water retention value (WRV)}

The WRV of the samples was determined via a centrifuge (LD4-2-A, Beijing Jinxinxing Medical Device Factory, Beijing, China). The speed was set to $3000 \mathrm{rev} / \mathrm{min}$, and the time was set to $15 \mathrm{~min}$. Approximately $1 \mathrm{~g}$ of the pulp sample (o.d. weight) was diluted in $60 \mathrm{~mL}$ of deionized water overnight at room temperature. Then the pulp was put into a copper tube with a 200-mesh copper screen at the bottom.

\section{Fines retention rate measurements}

The fines retention rate of the pulp sample was analyzed via a dynamic drainage machine (DDJ\#2, RAE Systems Inc, Sunnyvale, CA) according to TAPPI standard T261 cm-94.

\section{Zeta potential measurements}

The zeta potential was measured via a zeta potentiometric analyzer (AFG Analytic $\mathrm{GmbH}$, Leipzig, Germany). A voltage of $150 \mathrm{~V}$ was applied to the driving electrodes of the capillary electrophoresis cell. The electrophoresis cell was rinsed with HPLC-grade water to ensure the stability of the measurements before each use. The zeta potentiometric analyzer was calibrated using a standard (DTS5050, Malvern Instruments, Malvern, United 
Kingdom) with a standard zeta potential of $-50 \pm 5 \mathrm{mV}$ at $25^{\circ} \mathrm{C}$. All the experiments were conducted at $25^{\circ} \mathrm{C}$.

Scanning electron microscopy (SEM)

The scanning electron microscope (SEM) images of the paper sheets were analyzed via a field emission scanning electron microscope (FESEM) (SU8010, Hitachi, Tokyo, Japan) after gold sputtering. The accelerating voltage was $3 \mathrm{kV}$.

\section{RESULTS AND DISCUSSION}

\section{Effects of the Binary System on the Paper Properties}

Table 1 reports the effects of the bentonite dosage on the paper properties, which included the density, dry tensile index, wet tensile index, and folding endurance. When the only addition was $0.8 \%$ PAE resin, the density, dry tensile index, wet tensile index, and folding endurance were $0.576 \mathrm{~g} / \mathrm{cm}^{3}, 62.42 \mathrm{~N} \cdot \mathrm{m} / \mathrm{g}, 12.39 \mathrm{~N} \cdot \mathrm{m} / \mathrm{g}$, and 74 times, which improved by $2.5 \%, 15.9 \%, 1930 \%$, and $139 \%$ when compared to the control sample. When the bentonite was added, as the dosage increased, the four measured properties of the paper showed the same variation trend, which rapidly increased in the beginning, and then slightly decreased.

Table 1. Effects of the Bentonite Dosage on the Paper Properties

\begin{tabular}{|c|c|c|c|c|}
\hline $\begin{array}{c}\text { Dosage of } \\
\text { Bentonite (\%) }\end{array}$ & $\begin{array}{c}\text { Density } \\
\left(\mathrm{g} / \mathrm{cm}^{3}\right)\end{array}$ & $\begin{array}{c}\text { Dry Tensile } \\
\text { Index }(\mathrm{N} \cdot \mathrm{m} / \mathrm{g})\end{array}$ & $\begin{array}{c}\text { Wet Tensile } \\
\text { Index (N.m/g) }\end{array}$ & $\begin{array}{c}\text { Folding } \\
\text { Endurance } \\
\text { (Double Folds) }\end{array}$ \\
\hline Control & 0.562 & 53.84 & 0.61 & 31 \\
\hline 0 & 0.576 & 62.42 & 12.39 & 74 \\
\hline 0.25 & 0.587 & 67.21 & 13.93 & 80 \\
\hline 0.5 & 0.596 & 71.73 & 16.02 & 99 \\
\hline 0.75 & 0.612 & 74.21 & 17.58 & 118 \\
\hline 1.0 & 0.594 & 72.04 & 17.05 & 108 \\
\hline \multicolumn{4}{|l}{} \\
\hline
\end{tabular}

Compared to the control sample, the addition of $0.75 \%$ bentonite and $0.8 \%$ PAE resin yielded the highest measurements of density, dry tensile index, wet tensile index, and folding endurance, and reached a maximum of $0.612 \mathrm{~g} / \mathrm{cm}^{3}, 74.21 \mathrm{~N} \cdot \mathrm{m} / \mathrm{g}, 17.58 \mathrm{~N} \cdot \mathrm{m} / \mathrm{g}$, and 118 times, which represented an increase of $8.9 \%, 37.8 \%, 2780 \%$, and $281 \%$, respectively. The improvement of these properties was attributed to the increased bonding strength between the fibers. When the bentonite was added, due to the negative charge of its surface, the bentonite and PAE resin complexes were able to form and then were absorbed into the fiber surface; therefore, more PAE resin was retained in the paper compared to the paper when only PAE resin was added. However, when too much bentonite was added, the net charge of the suspended colloidal material (made up of PAE and bentonite and other matter) was negative, so it would not be as well retained on the fibers due to the negative charge of the fiber surface.

\section{Effect of the Binary System on the Fines Retention Rate}

The results of the effects of different bentonite dosages on the percent fines retention is shown in Fig. 1. It was found that the addition of PAE resin and the usage of a 
binary system both were able to improve the fines retention rate. When the only addition was $0.8 \%$ PAE resin, the fines retention was $59.4 \%$, which improved by $15.1 \%$ when compared to the control sample. When the bentonite was added, as the dosage increased from $0.25 \%$ to $1 \%$, the retention rate of fines continuously increased until the dosage was greater than $0.75 \%$, after which it decreased as the dosage approached $1 \%$. When dosages of $0.75 \%$ bentonite and $0.8 \%$ PAE resin were added, the fines retention rate reached a maximum of $77 \%$, which was a $49.3 \%$ increase when compared to the control sample. The increase in the fines retention rate could be attributed to the formation of weak cationic complexes composed of PAE resin and bentonite, which could help retain the fines. Given that fines are able to improve the bonding strength between the fibers, this result was consonant with the changes in the properties of the experimental papers (Table 1).

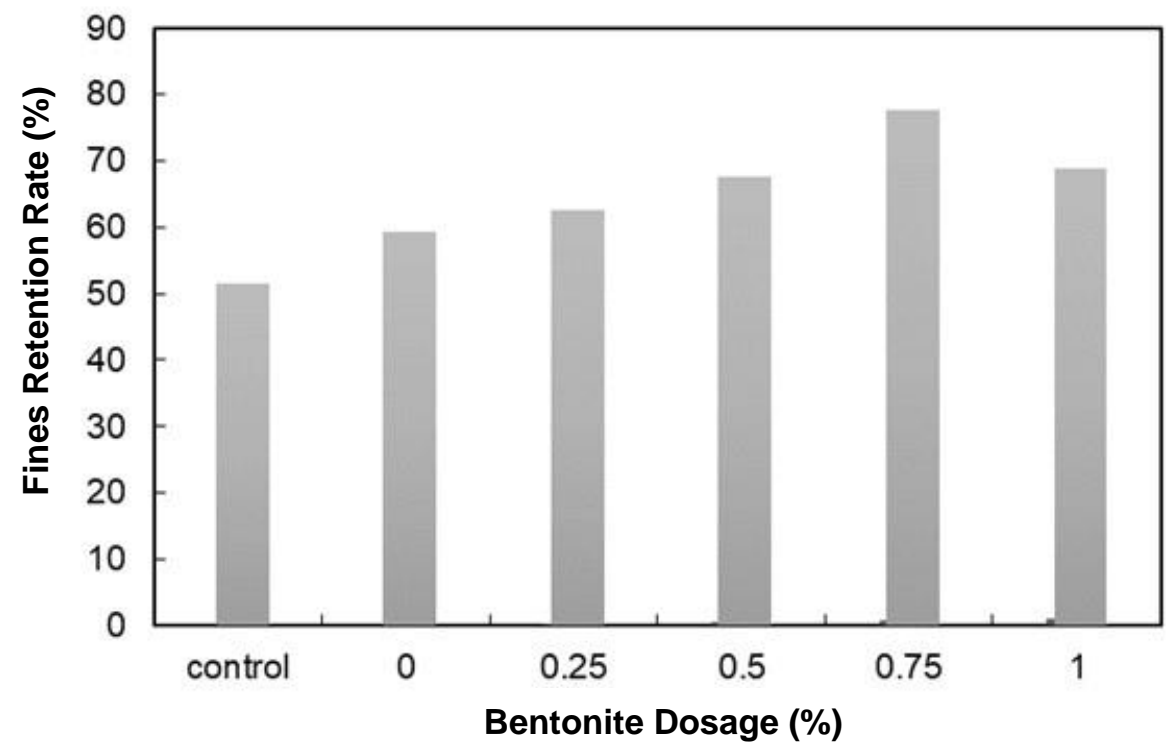

Fig. 1. Fines retention rate of the different dosages of bentonite (amount of PAE resin added was $0.8 \%$, on a dry fiber basis)

\section{Effect of the Binary System on the Water Retention Value (WRV)}

The WRV is an important index of the swelling ability of the fiber, which is usually adopted to evaluate the efficiency of the press dewatering of pulp. As shown in Fig. 2, when the pulp was treated with only $0.8 \%$ PAE resin, the WRV of the fibers increased by $116 \%$, when compared to the control sample. The binary system with the addition of bentonite further increased the WRV. As the bentonite dosage was increased, the WRV also increased until it reached a maximum value of 502\%, at a dosage of $0.8 \%$ PAE resin and $0.75 \%$ bentonite. The increase in the WRV reflected the increasing amount of water held by the PAE resin and bentonite on the surface of the fiber, which could be attributed to the charged groups of the two chemicals and their hydrophilicity. Furthermore, the increase in the WRV would also facilitate the bonding between fibers, which could lead to an increase in tensile strength. 


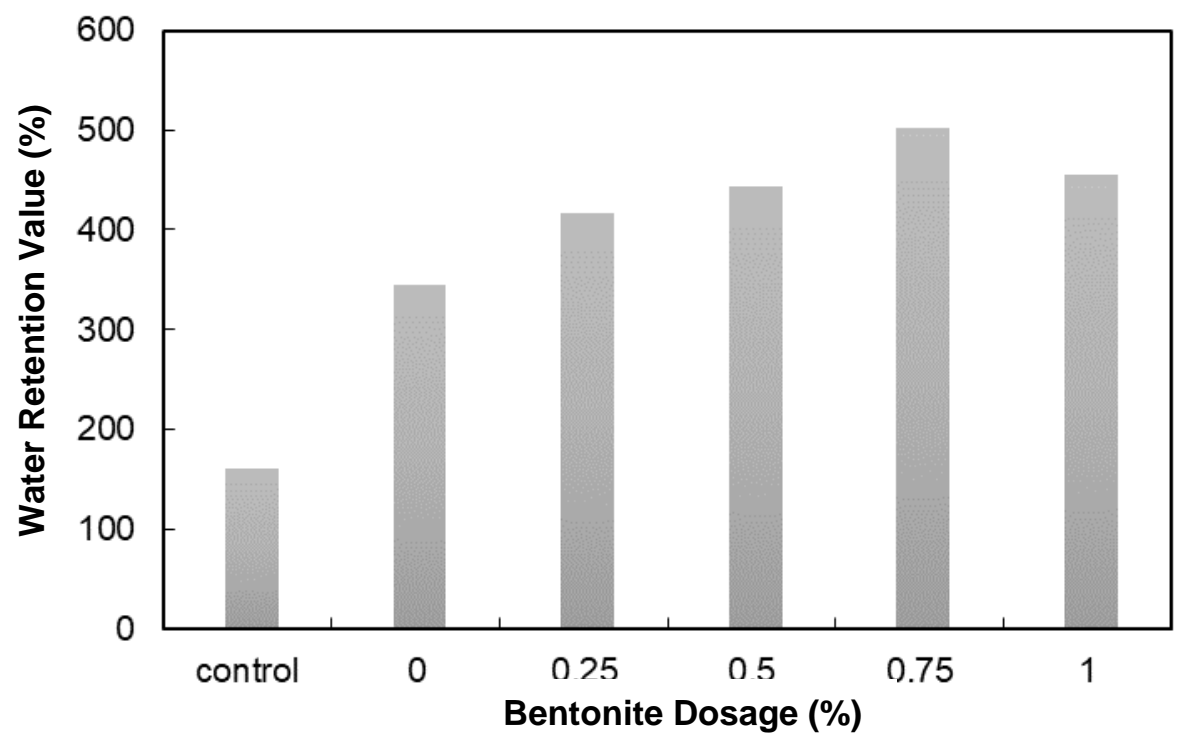

Fig. 2. Water retention value with different bentonite dosages (amount of PAE resin added was $0.8 \%$, on a dry fiber basis)

\section{Effect of the Binary System on the Zeta Potential}

The effects of the bentonite dosage on the zeta potential of the pulp are presented in Fig. 3. For the control sample (without any added additives), the zeta potential of the pulp was negative, due to the negative charge on the surface of the fiber. When the only addition was $0.8 \%$ PAE resin, the zeta potential was converted to positive, since the positively charged PAE resin groups were able to neutralize the negative charge on the surface of the fiber. When bentonite was added to the pulp in addition to a $0.8 \%$ PAE resin dosage, as the dosage of bentonite increased, the binary system caused the zeta potential of the pulp to slowly decrease.

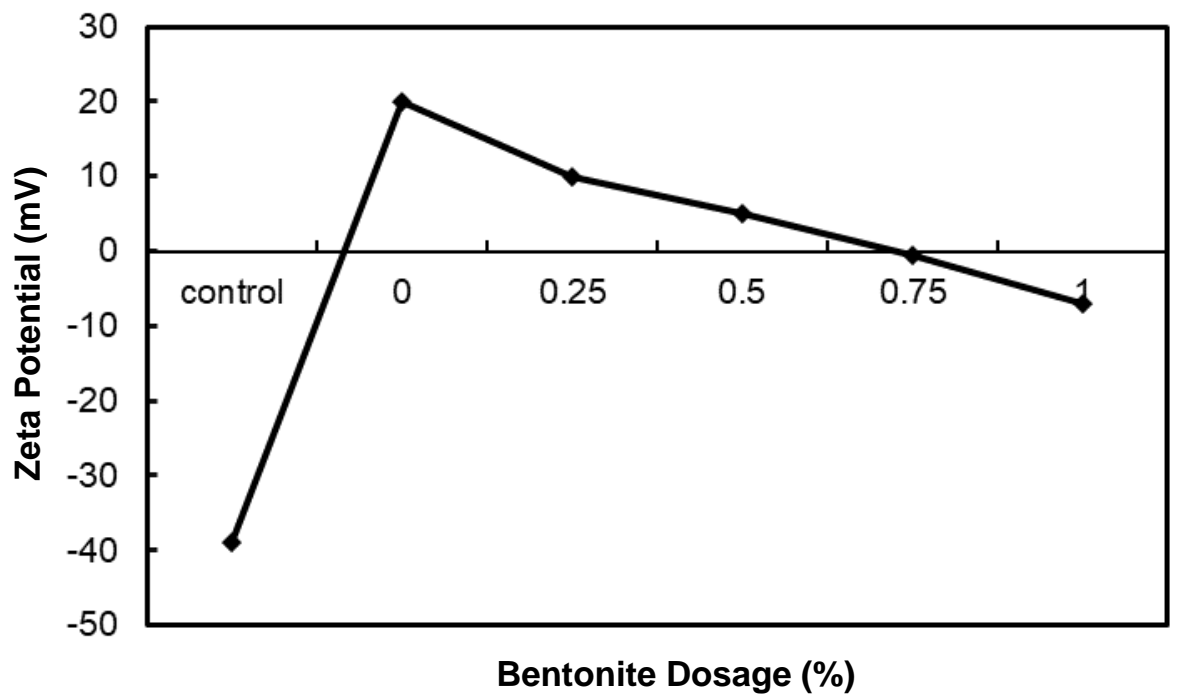

Fig. 3. Zeta potential value with different bentonite dosages (amount of PAE resin added was $0.8 \%$, on a dry fiber basis) 
As shown in Fig. 3, the zeta potential of the pulp approached 0 when dosages of $0.75 \%$ bentonite and $0.8 \%$ PAE resin were added. It is well-known that the addition of a strength agent would change the zeta potential of the pulp; therefore, when the zeta potential was approximately 0 , the dosage of the strength agent was the most appropriate and the maximum strength performance could be obtained at this dosage. This result was consistent with the data of paper properties shown in Table 1.

\section{Scanning Electron Microscopy (SEM) Analysis of the Handsheets}

The SEM images of the handsheet samples without any additives, with the addition of only $0.8 \%$ PAE resin, and the addition of $0.8 \%$ PAE resin and $0.75 \%$ bentonite, are presented in Fig. 4; obvious differences between the SEM images of the three handsheets could be seen.
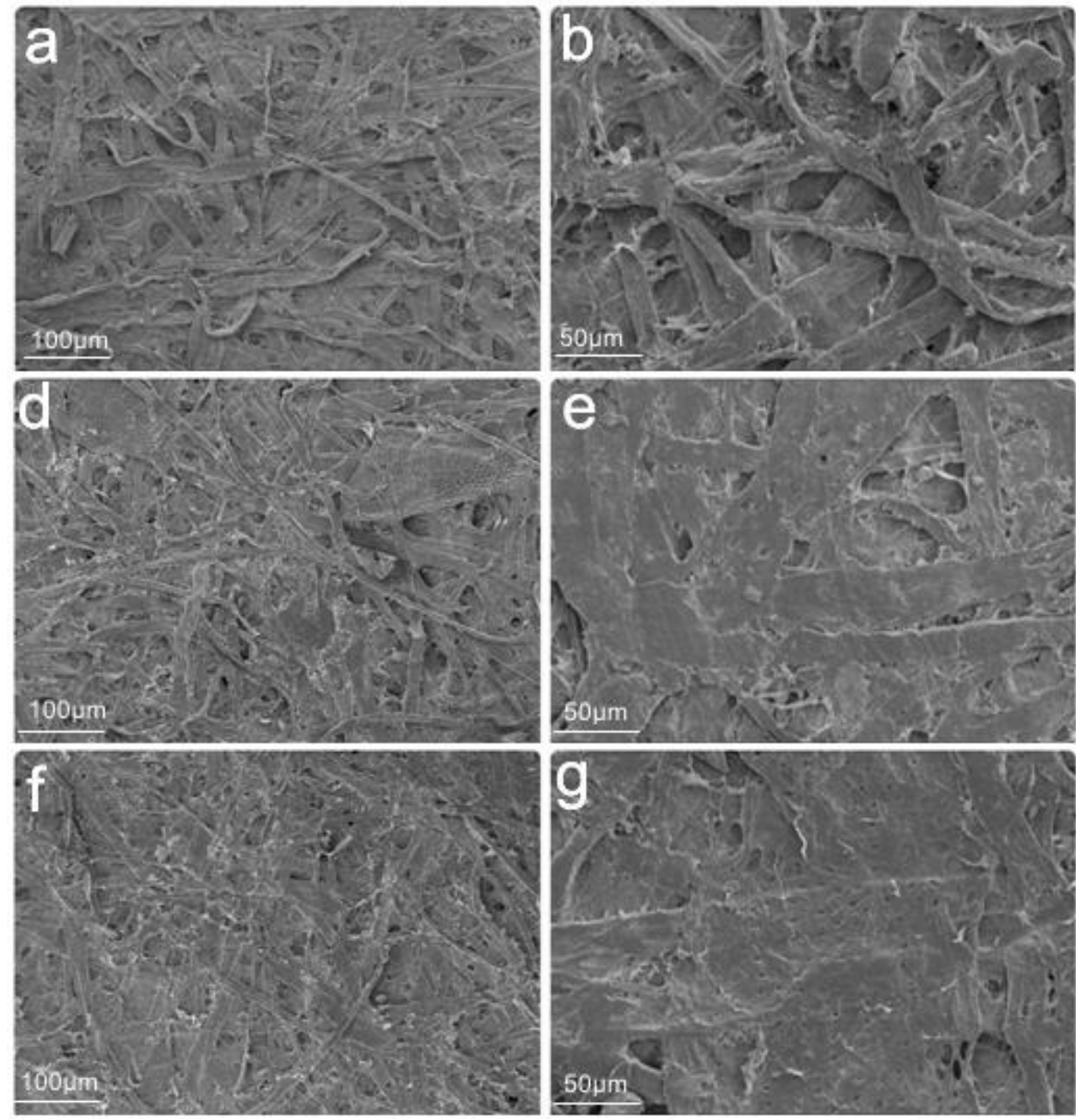

Fig. 4. Surface SEM images of control sample ( $a$ and $b$ ), handsheet with the addition of only $0.8 \%$ PAE resin ( $d$ and $e$ ), and handsheet with the addition of $0.8 \%$ PAE resin and $0.75 \%$ bentonite ( $\mathrm{f}$ and $\mathrm{g}$ ) 
There were more pores and the fibers were loosely connected to the surface of the control sample. Compared with the control sample, after being treated with PAE resin and bentonite, the connections between the fibers became tighter, and fewer holes were observed. These results can be attributed to the roles of PAE resin and the binary system increasing the bonding force among the fibers.

\section{CONCLUSIONS}

1. In this study, a binary system of PAE resin and bentonite could improve the mechanical strength of paper, with greater success than the addition of PAE resin alone.

2. A binary system of PAE resin and bentonite was beneficial to further improving the water retention value of the pulp and the retention rate of the fines, which was beneficial to the improvement of the bonding strength between the fibers.

3. Scanning electron microscopy (SEM) analysis showed that the bonding between the fibers was improved after treatment via a binary system of PAE resin and bentonite, thus improving the strength of the paper.

\section{ACKNOWLEDGEMENT}

The authors would like to give their thanks to the National Natural Science Foundation of China (31470605).

\section{REFERENCES CITED}

Aarne, N., Kontturi, E., and Laine, J. (2012). "Carboxymethyl cellulose on a fiber substrate: The interactions with cationic polyelectrolytes," Cellulose 19 (6), 22172231. DOI: $10.1007 / \mathrm{s} 10570-012-9793-2$

Anirudhan, T. S., and Ramachandran, M. (2015). "Adsorptive removal of basic dyes from aqueous solutions by surfactant modified bentonite clay (organoclay): Kinetic and competitive adsorption isotherm," Process Safety and Environmental Protection 95, 215-225. DOI: 10.1016/j.psep.2015.03.003

Aracri, E., Vidal, T., and Ragauskas, A. J. (2011). "Wet strength development in sisal cellulose fibers by effect of a laccase-TEMPO treatment," Carbohydrate Polymers 84 (4), 1384-1390. DOI: 10.1016/j.carbpol.2011.01.046

Bai, Y.-Y., Lei, Y.-H., Shen, X.-J., Luo, J., Yao, C.-L., and Sun, R.-C. (2017). “A facile sodium alginate-based approach to improve the mechanical properties of recycled fibers," Carbohydrate Polymers 174, 610-616. DOI: 10.1016/j.carbpol.2017.06.091

Chen, Z., Zhang, H., Song, Z., and Qian, X. (2013). "Combination of glyoxal and chitosan as the crosslinking system to improve paper wet strength," BioResources 8 (4), 6087-6096. DOI: 10.15376/biores.8.4.6087-6096

Deutschle, A. L., Römhild, K., Meister, F., Janzon, R., Riegert, C., and Saake, B. (2014). "Effects of cationic xylan from annual plants on the mechanical properties of paper," Carbohydrate Polymers 102, 627-635. DOI: 10.1016/j.carbpol.2013.12.016 
Gärdlund, L., Wågberg, L., and Gernandt, R. (2003). "Polyelectrolyte complexes for surface modification of wood fibres II. Influence of complexes on wet and dry strength of paper," Colloids and Surfaces A: Physicochemical and Engineering Aspects 218(1), 137-149. DOI: 10.1016/S0927-7757(02)00588-5

He, W., Wang, M., Song, X., and Zhao, Q. (2017). "Influence of carboxymethylated holocellulose and PAE binary system on paper properties," Cellulose Chemistry and Technology 51(3-4), 313-318.

Huang, Z., Li, Y., Chen, W., Shi, J., Zhang, N., Wang, X., Li, Z., Gao, L., and Zhang, Y. (2017). "Modified bentonite adsorption of organic pollutants of dye wastewater," Materials Chemistry and Physics 202, 266-276. DOI:

10.1016/j.matchemphys.2017.09.028

Hubbe, M. A. (2014). "Prospects for maintaining strength of paper and paperboard products while using less forest resources: A review," BioResources 9(1), 1634-1763. DOI: 10.15376/biores.9.1.1634-1763.

Hubbe, M. A., Jackson, T. L., and Zhang, M. (2003). "Fiber surface saturation as a strategy to optimize dual-polymer dry strength treatment," TAPPI Journal 2(11), 7 12.

Hubbe, M. A., Venditti, R. A., and Rojas, O. J. (2007). "What happens to cellulosic fibers during papermaking and recycling? A review," BioResources 2 (4), 739-788.

ISO 534 (2011). "Paper and board - Determination of thickness, density and specific volume," International Organization for Standardization, Geneva, Switzerland.

ISO 5269-2 (2011). "Pulps - Preparation of laboratory sheets for physical testing- Part 2: Rapid-Köthen method," International Organization for Standardization, Geneva, Switzerland.

Ning, X., Yao, C., Guan, L., and Bai, Y. (2018). "Fluorescent sodium alginate applied to papermaking furnish with polyamideamine epichlorohydrin," BioResources 13(4), 7519-7533. DOI: 10.15376/biores.13.4.7519-7533

Obokata, T., and Isogai, A. (2005). "Deterioration of polyamideamine-epichlorohydrin (PAE) in aqueous solutions during storage: Structural changes of PAE," Journal of Polymers and the Environment 13(1), 1-6. DOI: 10.1007/s10924-004-1210-y

Obokata, T., and Isogai, A. (2007). "The mechanism of wet-strength development of cellulose sheets prepared with polyamideamine-epichlorohydrin (PAE) resin," Colloids and Surfaces A: Physicochemical and Engineering Aspects 302(1-3), 525531. DOI: 10.1016/j.colsurfa.2007.03.025

Pandey, S. (2017). "A comprehensive review on recent developments in bentonite-based materials used as adsorbents for wastewater treatment," Journal of Molecular Liquids 241, 1091-1113. DOI: 10.1016/j.molliq.2017.06.115

Siqueira, E. J., Salon, M.-C. B., Belgacem, M. N., and Mauret, E. (2015). "Carboxymethylcellulose (CMC) as a model compound of cellulose fibers and polyamideamine epichlorohydrin (PAE)-CMC interactions as a model of PAE-fibers interactions of PAE-based wet strength papers," Journal of Applied Polymer Science 132(26), 1-10. DOI: 10.1002/app.42144

Su, J., Mosse, W. K. J., Sharman, S., Batchelor, W., and Garnier, G. (2012). "Paper strength development and recyclability with polyamideamine-epichlorohydrin (PAE)," BioResources 7(1), 913-924.

Sun, B., Hou, Q., Liu, Z., and Ni, Y. (2015). "Sodium periodate oxidation of cellulose nanocrystal and its application as a paper wet strength additive," Cellulose 22(2), 1135-1146. DOI: 10.1007/s10570-015-0575-5 
Sun, S., An, Q., Li, X., Qian, L., He, B., and Xiao, H. (2010). "Synergistic effects of chitosan-guanidine complexes on enhancing antimicrobial activity and wet-strength of paper," Bioresource Technology 101(14), 5693-5700. DOI: 10.1016/j.biortech.2010.02.046

TAPPI T220 sp-01 (2001). "Physical testing of pulp handsheets," TAPPI Press, Atlanta, GA.

TAPPI T261 cm-94 (1995). "Fines fraction by weight of paper stock by wet screening," TAPPI Press, Atlanta, GA.

TAPPI T511 om-08 (2008). "Folding endurance of paper (MIT tester)," TAPPI Press, Atlanta, GA.

Toor, M., Jin, B., Dai, S., and Vimonses, V. (2015). "Activating natural bentonite as a cost-effective adsorbent for removal of Congo-red in wastewater," Journal of Industrial and Engineering Chemistry 21, 653-661. DOI: 10.1016/j.jiec.2014.03.033

Wu, M., Lv, W., Wang, F., Long, Z., Chen, J., and Dong, C. (2018). "Preparation of dialdehyde chitosan/crosslinked amino starch and its effect on paper strength," Cellulose Chemistry and Technology 52(1-2), 43-49.

Article submitted: November 12, 2019; Peer review completed: March 21, 2020; Revised version received: September 9, 2020; Accepted: September 13, 2020; Published:

September 21, 2020.

DOI: $10.15376 /$ biores.15.4.8449-8458 